\title{
Arsenic Influence Variations in Animals by Its Toxicity
}

\author{
Hina Ayub* \\ University of Narowal, Pakistan \\ *Corresponding author: Hina Ayub, Department Zoology, University of Narowal, Pakistan; E-mail: hinarajpoot1112@gmail.com
}

Received: February 09, 2021; Accepted: February 13, 2021; Published: February 20, 2021

\begin{abstract}
There have been several revisions that have examined the effectiveness of chronic arsenic exposure in animals. Specifically, we aim to investigate the effects of arsenic trioxide on nephrotoxicity, hepatotoxicity, and nephrotoxicity. This section concludes by examining the impact of Arsenic. Taken together, these results suggest that Arsenic is a pollutant to both persons and animals. The conclusions got, in this case, hold globally that we have associated Arsenicals with skin, lung, and bladder cancers of the skin, lung and bladder. Arsenic (As) has both metallic and nonmetallic properties and is known as a metalloid. They contain it in ore, and it crushes rocks of an average density. This suggests complex chemistry, which exists in four separate valences (III, O, III, and V). And I have used it for a wider range of business and farming purposes in many chemical types. The most common arsenic compound used in industry is an arsenic oxide (As2O3), which is used to synthesize other inorganic and biological Weapons. For the prevention of acute pro-monocytic leukemia, arsenic trioxide is also being used. Absorption occurs mainly by ingestion in the small intestine, but through skin contact and respiration, fewer absorption orcs. Nausea, vomiting, stomach pain, extreme diarrhea and peripheral neuropathy were originally associated with acute arsenic poisoning. The multisystem disease may result from chronic arsenic poisoning.
\end{abstract}

Keywords: Arsenic (As), Arsenic oxide, Chronic poisoning, Neuropathy, Valence, Phosphorylation, Diseases

\section{Introduction}

Arsenic is a nonmetallic present mainly inland, atmosphere and in water from natural and human-made causes. It is volatile in biological forms and various states of oxidation $(-3,0,+3,+5)$. In terms of ecological exposure, toxicology of arsenic is mainly related to mild pentavalent oxidation state. Arsenic ionic form, arsenic acid ionic form, and arsenic compounds. Monomethyl arsonate acid (MMAV) and dimethyl arsenic acid (DMAV) are volatile arsenicstable methylated mammalian substances and are mainly expelled in the urine. DMAV and sodium salts of MMAV are used as weedkillers.

In the body of animals and vegetable cells, arsenic has been extensively studied for its poisonousness and healing use. It is found in petrifaction and soils ranging varies from 1 million to hundreds of $\mathrm{ppm}$, with an average range value of $2 \mathrm{ppm}$. In sulfide layers, many metals such as lead, copper sulfides, silver, and iron, arsenic with sulfides are present mainly.

High levels of arsenic were recorded in many areas of the world. A bearable arsenic amount of up to $1100 \mathrm{pg} / 1$ have appeared in drinking water in many places. Arsenic is also present in seawater.

Arsenic is used as an agricultural wood preservative, desiccant, and herbicide and a finishing agent for the goblet manufacturing and copper and lead mixtures. It is predicted as human emissions of arsenic at 41,000 metric tons every year. Worldwide discharges from ordinary resources are estimated at 7800 metric tons every year. Further input of marine arsenic encouraged the study of the accretion and lethal effects of aquatic organisms.

Regarding arsenic, most people think of it as a deadly toxin that has been used for periods. However, most human exposure to arsenic comes from sources such as drinking water, food, dust, and soil, although it is believed that low levels of arsenic are essential nutrients but it as adverse health effects. Although the concentration of exposure in drinking water depends on the determination of the current maximum container level (MCL) of $50 \sim \mathrm{g} / 1$ of arsenic.

It is narrated by [1] Arsenic (AS) is a common contaminant in various parts of the ecosphere. Arsenal and its derivatives are environmentally mobile. Rock decomposition changes arsenic sulfide to arsenic trioxide, which comes in the arsenic environment through the dust cycle or dissolves in rain, rivers, or water table. Chronic contact with organic arsenic can flow to skin, lung, vesica urinaria, and liver cancers.

These metalloids are generally toxic in various chemical forms; therefore, volatile shapes of arsenic (i.e., arenite, arsenate) are more Methylated forms (methyl methacrylate, MMA), dimethyl arsenate (DMA) are moderately examined toxins. Supplementary arsenic types, such as a trimethyl-arsenic oxide (TMAO) and tetra-methylarsonium (tetra), are also considered moderately toxic, as is arsenic betaine (ASB), arsenic choline (ASC), and other arsenic sugars (AS) does not show (Fatorini et al., 2006).

Numerous epidemiological revisions in diverse geographical zones have shown that mineral arsenic is a human cancer-causing agent. Though, the process of cancer is not yet known. Research on the absence of carcinogenesis in vivo animal representations [2] or in vitro cell systems is instrumental in clarifying the reasons for arsenic carcinogenesis. 
Some studies have reported that arsenic leads to gene enhancement, chromosomal abnormalities, of DNA repair inhibition, decreased DNA activity, and proton gene activation. Earlier, we stated that V79$\mathrm{Cl} 3$ (Chinese hamster cells) undertook early genetic uncertainty or programmed cell death when visible to sodium arsenic (S.A.).

In explanations made during and later dealing, genetic variability was evident in the existence of irregular and aneuploid cells, nonetheless chromosome abnormal cells. As mitotic cells became more sensitive to S.N. disclosure due to direct arsenic action in the mitotic spindle assembly, we later discovered the movement of hereditarily uneven cells that escape apoptosis by cutting mitotic round-up. The cell population was still not genetically stable when tested after two months of cell culture (120 cell generations).

Although there has been much progress in the field of synthetic drugs in recent years, they have had some or other side effects, but it has been suggested that naturopathy with phytochemicals may still be beneficial in many situations [3].

Arsenic is found in the blood as a brain barrier, where it has neurotoxic effects on many assemblies, such as the ganglia. Although the information on the impact of arsenic on the central nervous system (CNS) is incomplete, the basal ganglia appear to be sensitive to the toxins effects, such as 3-nitroprionic acid, succinic dihydroxy dip. If the basal ganglia's monoamine content can be modified by arsenic exposure, it affects the behaviour. Studies of locomotor activity in rats have been reported to reduce the levels of arsenic trioxide used. Defects in functional study work have also been reported. The data's inefficiency and the fact that the results of the dose and exposure time have not been examined in previous studies make it difficult to conclude the effects of arsenic on the nervous system in the in vivo model. To research the neurotoxic consequence of arsenic exposure and assess the ace of basal ganglia for roles such as learning, remembrance, and movement, it is essential to determine whether arsenic revelation alters these compound functions.

Arsenic can induce male reproductive toxins such as the dosedependent reduction in testes and associated genital weight [4]. It can reduce the number of epididymal sperm [5], function, and motility [6]. The general form and the antioxidant, immune system [7]. There is an increase of hormones like Luteinizing hormone (L.H.), folliclestimulating hormone (FSH), testosterone, and massive depletion of germ cells in testicular tissue [8] Arsenic poisoning. Oxidative stress and the production of reactive oxygen species (ROS) may be a consequence of arsenic exposure [9]. Several protein functions can be modified to produce ROS and bind to arsenic protein thiol groups [10]. Such as arsenic on oxidative stress and DNA damage caused by ROS production [11]; Biswas RPS, 2007.

The International Agency classifies inorganic arsenic for Research on Cancer. Human cancer is known to the U.S. Environmental Protection Agency. This arrangement is based on numerous epidemiological revisions showing arsenic exposure and cancer development. Fowler's solution (potassium arenite), proficient introduction to inhaled copper smelters, or logically polluted drinking water. Cancers that occur later arsenic inhalation are mainly found in the lungs, although they are first detected on the skin subsequently exposure to arsenic. However, the following studies suggest that people who regularly consume arsenic-contaminated drinking water are more likely to develop internal organ cancer. Tumor sites include the bladder, liver, and kidneys. Even though there is enough indication to classify arsenic as human cancer, it is unclear whether it happens in research laboratory animals. In many studies, animals have no cancer effect after exposure to inorganic arsenic for the rest of their lives after drinking, feeding, or oral hatching. It has been testified in rats, dogs and monkeys. Mice reveal to arsenic in drinking water for 26 weeks did not develop tumors. However, several positive information about arsenic cancer in animal samples. In the 1980s, numerous studies reported transient arsenic cancer in hamsters after intratracheal insulation. This direction has been used to mimic arsenic respiration. In these studies, it includes used of chemicals i.e., arsenic trioxide (As2O3), calcium arsenate $(\mathrm{Ca}(\mathrm{AsO} 4) 2)$, and arsenic trisulfide (As2S3). Tumors were examined once a week for 15 weeks, and tumors were examined during life.

\section{Data Collection}

PubMed has conducted a literary search using the Google Scholar and Science-Hub database to identify relevant studies from the past to the present. Summary of studies stated on introduction to arsenicpolluted drinking water.

Using a verified reference list from former review articles, I searched manually for more relevant studies to identify studies that could not be recovered over an electronic record. We only consider peer-review journals and articles published in English. Each selected report critically assessed and summarized the range of relationships between position, design, organ impact, sample size, exposure assessment, arsenic exposure, and development.

\section{Ancient Beneficial Uses of Arsenic}

In ancient times arsenic was used as an attenuating representative after Greek doctors such as Hippocrates and Galen popularized its use. With that arsenic complexes are found in the form of solutions, tablets, pastes, and injection forms. Utmost recently, in 1958, the British Pharmacological and Therapeutic Products Handbook, revised by Martindale, listed indications for Fowler's solution: leukemia, skin conditions. Fowler's solution is also indicated as a health energizer.

\section{Current Beneficial Uses of Arsenic}

Arsenal trioxide (AS2O3), and endosperm based on its structure, is now widely used in patients with severe primality rocambole withdrawal [12]. Arsenal insisted on apoetical [13]. AIF then affects programmed cell death, resulting in nuclear biochemistry, chromatin condensation, DNA fragmentation, and cell death. Arsenic is often an additive, sometimes mercury and lead [14]. The California Department of Health retail displays 251 products in herbal goods, and 36 products $(14 \%)$ contain arsenic.

\section{Coal naturally has High Arsenic Levels}

As most coal has arsenic content of fewer than 5 milligrams per kilogram, ordinary coal is low in arsenic, which is less harmful 
to human health. Some coal can, however, comprises up to 35000 mg per $1 \mathrm{~kg}$ of coal [15]. Numerous research studies have shown how indoor air can be polluted by burning high arsenic coal. For instance, P.R. The effects of coal-burning have been investigated on residents of Guizhou Province, China. Coal, water, air, food, urine, and hair samples from local and limited zones were obtained and arsenic examined.

\section{Chronic Arsenic Poisoning}

Arsenic poisoning processes include the inhibition of the substitution of cellular enzymes comprising the community of sulfides and phosphate molecules in 'amino lysis' [16]. In inhibiting enzymes, trivalent arsenic complexes are more effective, while arsenic lysis is done by pentavalent compounds [16]. Trivalent is a human carcinogen, including mild bronchogenic carcinomas, hepatic angiosarcomas [17], and intradermal carcinomas (Bowen's disease) [18]. Carcinomas of squamous cells, carcinomas of basal cells, and 'integrated' types of skin cancer [16]. Myelogenous leukemia can occur as well [19]. French gold miners are more vulnerable to Hodgkin's disease. Arsenic Exposed [20]. Flow The repeated use of Fowler solution or arseniccontaminated drinking water has been associated with lung, liver, bladder, and kidney cancers [17].

\section{Acute Arsenic Poisoning}

Overdose can lead to serious reactions such as diarrhea, vomiting, pain, desiccation, and faintness. Nowadays, severe intoxication is very rare in Western European countries; if that happens, it is usually the result of intentional (suicide or homicide) or accidental poisoning. Professional exposure to as is infrequent and usually occurs in the form of arsenic gas. It causes different symptoms due to eating [21]. Exposure often occurs when arsenic gas escapes during transport or production. Minerals or metals containing arsenic are treated with acid [22,23]. It is associated with gastrointestinal disorders. Cardiac and pulmonary symptoms include hypotension, shock, pulmonary oedema, and cardiac arrest.

\section{Arsenic Exposure}

Exposure of arsenic is caused through skin, and by the usage of contaminated drinking water. Arsenic in the diet occurs as comparatively nontoxic organic compounds. Seafood, fish, and algae are rich in biological resources [24]. These organic compounds increase the level of arsenic in the blood but do not change in the urine [25]. Arsenic consumption is higher in solid foods than in liquids, including drinking water [26]. Organic and volatile arsenic compounds may enter the vegetarian diet from farming goods or soils cultivated with arsenic contaminants [27].

\section{Absorption}

The gastrointestinal tract is the leading absorption process by an electronic process with a proton gradient (Gonzalez et al., 1997), The normal pH range for arsenic absorption is 5.0, and (Silver et al. (1984) found that the small intestine' $\mathrm{pH}$ is approximately 7.0 after pancreatic bicarbonate secretion. (Ratnayake et al., 2000).

\section{Evolution}

Arsenic poisoning changes with its oxidation conditions. Organic types are usually more toxic than in organic matter. Arsenic (AsIII) is 60 times more toxic than arsenate. This latter species is 70 times more toxic than the methylated species, with Monomethyl arsenic acid (MMA) and dimethyl arsenic acid (DMA), the last two forms being considered only moderately toxic [28]. In mammals, arenite was methylated by depletion, arenite methyltransferase [28].

The absorbed arsenic endures hepatic biomethylation and forms Monomethyl arsenic acid and dimethylarcinic acid, which are nontoxic but ultimately harmless [29]. 50\% of the dose may be excreted in the urine. In three or five days. The metabolism of dimethylarginine acid $(60 \%-70 \%)$ in urine contrasts with Monomethyl arsenic acid [30]. Small amounts of inorganic arsenic do not change. Spectrometry studies of electrothermal nuclear absorption after acute poisoning show high arsenic levels in the kidneys and liver. In the muscles, nervous system, small intestine, and spleen [31]. Although most arsenic was removed from these sites, the remaining keratin remains in tissues, nails, hair, and skin. After about two weeks, arsenic will be dumped on the hair and nails.

\section{The Biological Cycle of Arsenic}

In water, mostly arsenic can be found in the form of arsenic or arsenic. There are also methylated arsenic compounds that arise naturally in the environment due to biological activity (Craig et al., 1989). Coal industrial metal smelting (Tomaki et al., 1992) and the semiconductor industry [32] are major sources of pollution and labor exposure to arsenic. Arsenic poisoning depends largely on its oxidation status: arsenic is 100 times more toxic than pentavalent derivatives [33]. The toxicity of arsenic (IAS) is due to the protein binding to sulfhydryl groups [34]. Insoluble arsenide's can be converted to soluble forms of arsenate and arenite by industrial methods and fecal smelting. The presence of arsenate, arsenic, and methyl-arsenic can be found in exposed individuals [35]. Biological redox reactions alter arsenic and arsenate, and arsenic can be methylated by bacteria, fungi, and algae [36]. Few organisms such as algae and crustaceans focus on arsenic well over the level in the environment. The arsenic biotic cycle in nature is summarized in Figure 1.

\section{Arsenic Accumulation in Water Biota}

\section{Plankton}

Because of phytoplankton's role in defining the fundamental properties of seawater, very little has been available about the total arsenic in plankton. They report the total arsenic concentration of three zooplankton species from seawater in the Northeast Atlantic Ocean to be 14 to 42 grams g dry weight [37]. I have reported similar or smaller attentions from other waters. Recently, arsenic is directly toxic to zooplankton. However, it is present in top levels in solution. Its effect on phytoplankton species structure (in favor of tolerant species) may be significant aspects of coastal phytoplankton and zooplankton-water. Arsenic data in echinoderms are minimal [38] found a high aggregation of total arsenic (varying depending on 


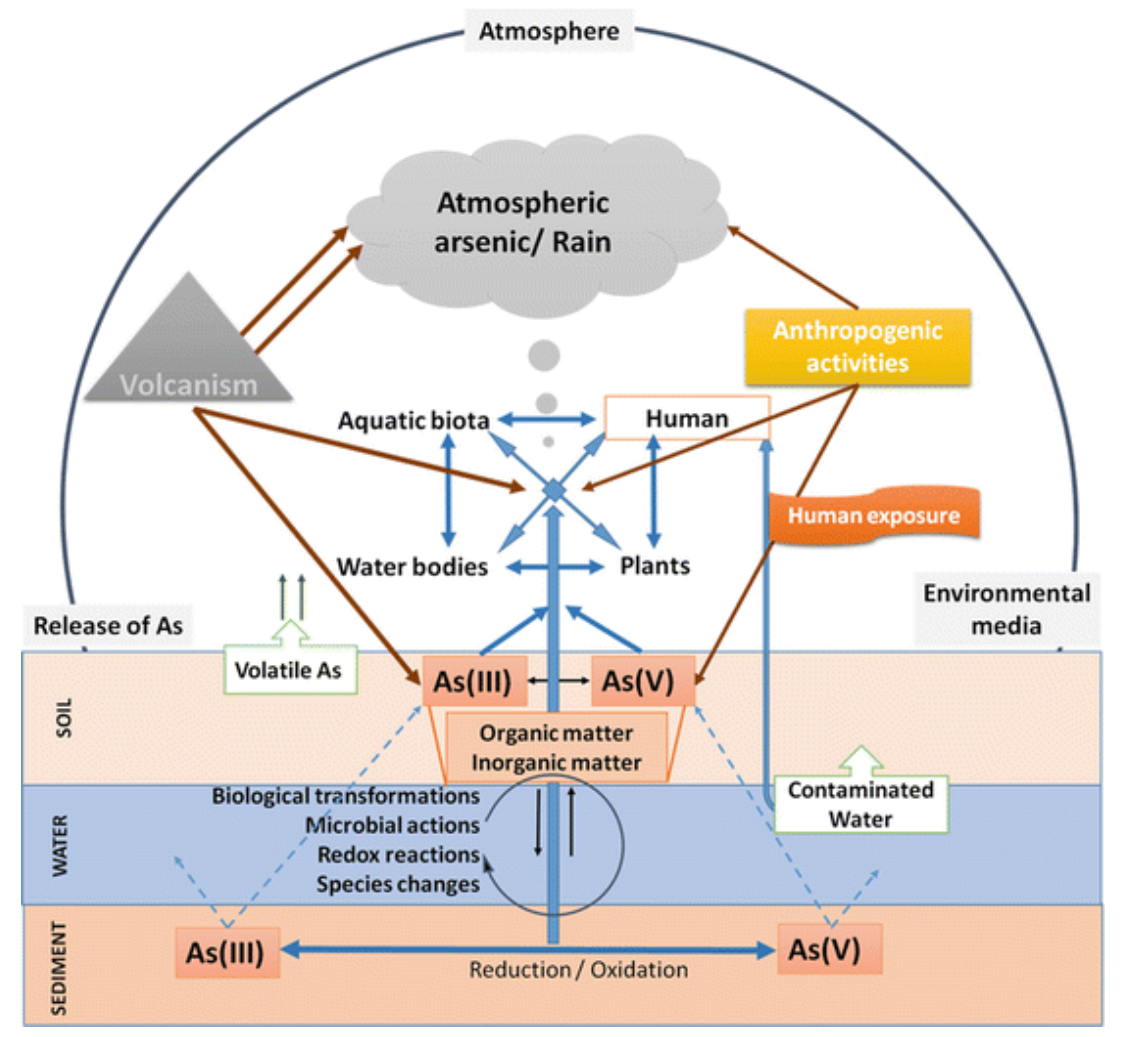

Figure 1: Arsenic biological cycle in nature.

the sample's location) in the lipids of many organisms. A study [37] reported that the asteroids Metaseries Glacier and Asterias Rubens of Portland, Dorset, had a dry mass of 5.8 and 10 grams, respectively.

The total arsenic level in most polycystic is not significant. For example, Neris has been reported to have a g-1 dry weight of 4 to 87 grams of the diverse color element, depending on Madis's region.

The other thing, discrete data on arsenic are present in other aspects than those discussed above. For example, it is reported by [37], From the North Atlantic Ocean, $72 \mu \mathrm{g} g-1$ arsenic weight of telefelony from Southampton waters, but low concentrations (2.8-6.6 g -1 dry weight) in one sponge and two tunicate materials.

\section{The Mechanism of Arsenic Poisoning in Modern Pregnancy Targets}

Methods by which exposure to arsenic adversely affects pregnancy are not completely understood; however, some potential methods based on investigational evidence have been proposed. Arsenic occurs as part of organic compounds or volatile compounds in elemental form. The predominance of volatile species in water is [39]. By rapid urination or a continuous methylation procedure that occurs mostly in the liver, volatile arsenic is extracted from the body [40]. An association between arsenic venomousness in swallowing water and contrary effects on pregnancy has been found in numerous epidemiological studies.

\section{Effect of Arsenic on the Skin}

Most skin changes occur with chronic exposure. (Lyon et al., 1994), Dermatologic changes are communal, and the primary clinical analysis is often founded on hyperpigmentation, palmar, and solar keratosis. Keratosis appears as a single lump or separate nodule. Arsenic is a non-melanin pigment that can cause basal cell carcinoma in the skin [41].

Although human skin is more susceptible to arsenic poisoning and carcinogenicity, wildfire rat skin models with carcinogenicity do not respond well to arsenic. Mouse skin is sensitive to most chemical cancers; rat skin is not very sensitive to chemical carcinogens.

\section{Arsenic Deficiency in the Nervous System}

The main target of many metals' toxic effects is the nervous system, especially heavy metals such as mercury, lead, and arsenic. Edgy products are many and varied. Peripheral neuropathy is the most common finding that mimics Guillain-Barre disorder with similar electromyographic results [42] Glove at the beginning of neuropathy and storage is sensitive to anesthesia.

Improved oxidative stress is an important component in arsenicinduced neurotoxicity. It is found that the main to cause oxidative damage to ecosystems is due to arsenic exposure by increasing free radical species [1], leading to enlarged lipid peroxidation and protein carbonyl. In addition, GSH levels decreased [1,43]. Glutathione is an important molecule involved in the fight against toxins. Decreases in GSH levels after arsenic exposure are related to higher arsenic interactions with GSH [44].

Because neurotransmitters play a significant role in modulating the behavioral and signaling cascade, several experimental studies have been conducted to investigate the arsenic effect on their levels 
and metabolic activity [45]. Changes in dopaminergic, cholinergic, serotonergic, and glutamatergic systems have been reported in arsenic-infected rats and mice. Differences in exposure pathways did not result in consistent changes in brain neurotransmitter levels, however, prolonged exposure to arsenic reduced dopamine levels in the striatum and brain [46].

\section{Effect of Arsenic on the Liver}

Arsenic treatment involves histological changes in hepatic tissues, including cytoplasmic vacuuming, cell degeneration, and focal necrosis. Accumulation of neutrophils and lymphocytes leads to deterioration of liver tissue and necrosis of the central vein. Similar results in liver pathology in mice confirm our products. In the current study, reduced $\mathrm{Hb}$ in the blood and increased bilirubin levels may be due to changes in hematopoietic function caused by arsenic intoxication, which corresponds to [47]. Arsenic compound [48] is a protoplasmic toxin. Arsenic property considered the mechanism for its toxic effect.

The onset of oxidative stress after contact with hepatotoxic agents is an essential factor in primary chronic liver disease associated with fibrosis. Membrane molecules that harm membrane lipids, building blocks of proteins (amino acids), sugars (carbohydrates), and nucleic acids are the major components of chemically persuaded hepatocellular injury. The liver [49] is the site of metabolism of many chemicals, counting mineral arsenic in many animals, including mammals. It acts as an essential antioxidant to reduce GSH in hepatocytes.

Biochemical and structural sign of arenite-induced changes in rat liver also with changes in development of rat has been found. Evidence includes GSH levels, hepatocyte nuclei, an intermittent vacation of hepatocytes, and sinusoidal dilatation in arsenic-fed animals. To recognize the exact mechanisms fundamental arsenic toxicity at the cellular and molecular levels, extensive studies using different doses of sodium arenite, and different lengths of exposure to diverse growing periods should be measured.

\section{Effect of Arsenic on the Kidneys}

Kidneys are prone to arsenic-induced damage due to extensive perfusion and increased concentration of excretory compounds in renal tubular cells [50]. Our results confirm increased serum urea, uric acid, and creatinine levels in the excretion of high levels of arsenic metabolism by renal tubular cells, which are more prone to damage and kidney problems.

Arsenic trioxide affects bone marrow, kidneys, and hemoglobin metabolism [51]. Any substance that significantly affects red blood cell values and associated parameters has been shown to affect the bone marrow, kidney, and hemoglobin metabolism.

In the present study, arsenic intoxication induced significant hepatic and renal oxidative stress, resulting in decreased cellular antioxidant enzyme activity, consistent with previous reports [52-56].

\section{Conclusion}

Arsenic compounds are toxic substances that can significantly affect the health of animals. Arsenic poisoning has been confirmed to be related to its chemical forms. Although most are known to affect mammals' signaling pathways, in this evaluation, we associated phosphorylation spots in diverse mammal and nonmammalian species.

As a result, we can assume that the same effects found in mammalian specimens of aquatic life are likely to occur. Also, arsenic has been shown to cause oxidative tension in mammals and nearly marine organisms. Current work shows that animals intoxicated with arsenic trioxide show significant impairment of liver function and kidney function. There are reports that the effects of AS exposure on the development of sensory systems are minimal. It is also likely to cause significant changes in specific biochemical parameters, including the liver and kidneys. There is reliable and consistent evidence to support an optimistic relationship among high levels of inorganic arsenic exposure to drinking water, miscarriage, stillbirth, and low birth weight.

\section{Acknowledgement}

I want to give all my credit to my parents and all author's whose article I have been considered for my publication.

\section{References}

1. Flora SJS, Bhadauria TS, Panta SC, Dhakade RK (2005) Arsenic-induced blood, brain oxidative stress, and reaction to specific thiol chelators in rats. Life Sciences 77: 23242337. [crossref]

2. Caceres DD, Pino P, Montesinos N, Atalah E, Amigo H, et al. (2005) Exposure to inorganic arsenic in drinking water and total urinary arsenic concentration in a Chilean population. Environmental Research 98: 151-159. [crossref]

3. Tripoli E, La Guardia M, Giammanco S, Di Majo D, Giammanco M (2007) Citrus flavonoids: Molecular structure, biological activity and nutritional properties: A review. Food Chemistry 104: 466-479.

4. Van Geen A, Radloff K, Aziz Z, Cheng Z, Huq MR et al. (2008) Comparison of arsenic concentrations in simultaneously-collected groundwater and aquifer particles from Bangladesh, India, Vietnam, and Nepal. Applied Geochemistry 23: 3244-3251.

5. Jana K, Jana S, Samanta PK (2006) Effects of chronic exposure to sodium arsenite on hypothalamo-pituitary-testicular activities in adult rats: possible an estrogenic mode of action. Reproductive Biology and Endocrinology 4: 9. [crossref]

6. Mukherjee S, Mukhopadhyay P (2009) Studies on arsenic toxicity in male rat gonads and its protection by high dietary protein supplementation. Al Ameen J Med Sci 2: 73-77.

7. Manna P, Sinha M, Sil PC (2008) Arsenic-induced oxidative myocardial injury: protective role of arjunolic acid. Archives of toxicology 82: 137-149. [crossref]

8. Guvvala PR, Sellappan S, Parameswaraiah RJ (2016) Impact of arsenic (V) on testicular oxidative stress and sperm functional attributes in Swiss albino mice. Environmental Science and Pollution Research 23: 18200-18210. [crossref]

9. Shi H, Shi X, Liu KJ (2004) Oxidative mechanism of arsenic toxicity and carcinogenesis. Molecular and Cellular Biochemistry 255: 67-78. [crossref]

10. Wang TC, John KY, Wang AS, Gurzar (2007) Trivalent arsenicles cause lipid peroxidation, protein carbonization, and oxidative DNA damage in human urothelial cells. Mutat Res 615: 75-86. [crossref]

11. Balakumar B, Ramanathan K, Kumaresan S, Suresh R (2010) DNA damage by sodium arsenite in experimental rats: ameliorative effects of antioxidant vitamins $\mathrm{C}$ and E. Ind J Sci Tech 3: 322-327.

12. Shen ZX, Chen Zik, Ni JH, X S Li, S M Xiong et al. (1997) Use of Arsenic Trioxide (AS2O3) in the Treatment of Acute Promyelocytic Leukemia (APL): II. Clinical efficacy and pharmacokinetics in rehabilitated patients. Blood 89: 3354-3360. [crossref]

13. Lorenzo HK, Susin SA, Penninger J, G Kroemer et al. (1999) Apoptosis-Inducing Factor (AIF): The phylogenetically old, caspase-free effect of cell death. Cell Death Difference 6: 516-24. [crossref] 
14. Co RJ (1999) Causes of herbal poisoning, epidemiology, and clinical evaluation. Clin Toxicol 37: 697-708. [crossref]

15. Ding Z, Zheng B, Long J, Belkin HE, Finkelman RB, et al. Guizhou, in the southwestern province of China. Applied Geochemistry 16: 1353-1360

16. ATSDR (1990) NVSDR Case Studies in Environmental Medicine. Agency for Toxic Substances and Disease Registry, Atlanta GA, USA.

17. Bates MN, Smith AH, Hoppenhein-Rich C (1992) Arsenic addiction and internal cancer: A review. Am J Epidemiol 135: 462-476. [crossref]

18. Gochfeld M, (1995) Chemical agents. Of: Brooks S, Gochfeld M, Herstein J, et al. Environmental Medicine 592-614.

19. Keldesburg cR, Ward HP (1972) Leukemia in arsenic poisoning. On Intern Medal 77: 935-937. [crossref]

20. Simonato L, Malin Lynn JJ, Javalad B, Ferro G, Wilde P, et al. Refinery in France. Am J 25: 625-633

21. De Wolf FA, Edelbrock PM (1994) Neurotoxicity of arsenic and its compounds. Vincennes \& Bruin, Vol. Handbook of Clinical Neurology. Elsevier Science 1994: 283-291.

22. Wilkinson SP, McHugh P, Horsley S, Tubbs H, Louis M, et al. (1975) Br Med J 3: $559-63$.

23. Pullan-James S, Woods SE (2006) Professional arsenic gas exposure. J Not Med Ashok 98: 1998-2001

24. Edmunds JS, Francisco KR (1987) Arsenic is converted into the marine environment. Experiment 43: 553-557

25. Bouchet JP, Liegen D, Ruggery M, et al. (1996) Estimating inorganic arsenic exposure to human cancer due to fish consumption. Arch Toxicol 70: 773-778.

26. Thomas KW, Pellissery ED, Berry M (1999) Demographic Diet and Tap Water Density for Selected Factors for EPA Region v. National Human Exposure Assessment Survey (NHAS). J Expo Anal Environment Epidemiol 9: 402-413.

27. Tomaki S, Frankenberger WT Jr (1992) Environmental Biochemistry of Arsenic. Rev Environment Condom Toxicol 124: 79-110. [crossref]

28. Actor KF, Owens G, Davy DE, Naidu R (2005) Arsenic Specification and Toxicity in Biological Systems. Rev Environment Condom Toxicol 184: 97-149. [crossref]

29. Thompson DJ (1993) A chemical theory for the arsenic methylation in mammals. Chem Biol Interact 88: 89-114. [crossref]

30. Hoppenhein C, Ferrexio C, Browning SR, Huang B, Peralta C et al. (2003) Birth weight from drinking water, birth weight. Epidemiology 14: 593-602.

31. Ghosh P, Banerjee M, De Chaudhuri S, Chowdhury R, Das JK, et al. (2007) Comparison of health effects between individuals with and without skin lesions in the population exposed to arsenic through drinking water in West Bengal, India. Journal of exposure science \& environmental epidemiology 17: 215-223. [crossref]

32. Kedelman p (1999) Environmental and Office Appreciation of the Semiconductor: Implications) The Future of the Labor Force and Society. The Environment $T$ Wealth Perspective 6: 291295

33. Knowles FC, Benson AA (1983) Arsenic Biochemistry. Trends Biochem Science. 8: 17818

34. Summer AO, Silver s (1978) Microbial transformations of metals. That day. Rev Microbiol 32: 637-672.
35. Farmer JG, Johnson L (1990) Inorganic Arsenic Exposure Assessment Based on Urine Concentration and Arsenic Specification. Br J Med 47: 342-348.

36. Hughes m, Pool RK (1989) Metals and microorganisms. Chapman \& Hall, London

37. Leatherland TM, Burton JD, Kalkin F, McCartney MJ, Morris RJ (1973) Concentrations of certain metals and mercury in pelagic organisms in the waters of the Northeast Atlantic Ocean. Deep Sea Res 20: 679-685.

38. Vaskovsky VE, Korochenko OD, Kosheleva LP, Lenin VS (1977) Arsenic in marine invertebrate lipid extract. Comp Biochem Physiol 41: 777-784.

39. International Agency for Research on Cancer (2012) Arsenic, metals, fibers and dust particles. Review of human cancer factors; International Agency for Research on Cancer, World Health Organization: Geneva, Switzerland.

40. Albiac J, Calvo E, Tapia J, Esteban E (2010) Water quality and nonpoint pollution: Comparative global analysis. Re-thinking Water and Food Security 251.

41. Abernathy CO, Liu YP, Long Fellow D, et al. (1999) Arsenic: health effects, mechanism of action, and research issues. Environment Health Perspective 107: 593 597. [crossref]

42. Goddard MJ, Tanheko JL, Dow PC (1992) Massage of chronic arsenic poisoning as a laundry-Guillain-barre syndrome. Electromyography Clin Neurophysiole 32: 419-423. [crossref]

43. Shila S, Kokilawani V, Subhadra M, Panneerselvam CB (2005) Local brain response in the antioxidant system to $\alpha$-lipoic acid in arsenic-mice. Toxicology 210: 25-36. [crossref]

44. Apocalypse HV, Apocalypse MM (1989) New developments in arsenic poisoning. J Colonel Toxicol 8:1297-1305.

45. Rodriguez VM, Jimenez-Capdeville ME, Giordano M (2003) The effects of arsenic exposure on the nervous system. Toxicology Letters 145: 1-18. [crossref]

46. Krishnan GM, Tripathi N, Dubey SN, Gupta M, Flora SJS. J Toxicol Clin Toxicol 39: 675

47. Patrick L (2003) Toxic metals and antioxidants: part II. The role of antioxidants in arsenic and cadmium toxicity. Alternative Medicine Review 8: 106-128. [crossref]

48. Chattopadhyaya S, Bhumik S, Nagdhadhari A, Dasgupta S (2002) Arsenic changes in vivo, tissue culture, neonatal and adult brain cell growth and apoptosis. Toxicol Let 128: 73-84

49. Wahr M (2009) Effects of arsenic on maternal and fetal health. Annu Rev Nutter 29: 381-399. [crossref]

50. Verma RJ, Vasu A, Zayed AA (2004) Arsenic poisoning in rats and its possible improvement. J Environment Science 16: 447-453.

51. Young NS, Masijevsky J (1997) The Path Physiology of Acquired Aplastic Anemia. New Engine J Med 336: 1365. [crossref]

52. Wang TC, Jan KY, Wang AS, Gurr JR (2007) Trivalent arsenicals induce lipid peroxidation, protein carbonylation, and oxidative DNA damage in human urothelial cells. Mutation Research 615: 75-86. [crossref]

53. Apocalyptic HV (1997) Enzymatic methylation of arsenic species and other mechanisms for arsenic poisoning. On Rev Pharmacol Toxicol 37: 397-419. [crossref]

54. Majumder C (2018) Arsenic (V) removal using activated alumina: Kinetics and modeling by response surface. Journal of Environmental Engineering 144: 04017115.

55. Nordman R (1994) Alcohol and antioxidant systems. Alcohol 29, 513-522. [crossref]

56. Arsenic Biological cycle available at (https://images.app.goo.gl/JMbwElouWoQRcPuQA)

\section{Citation:}

Ayub H (2021) Arsenic Influence Variations in Animals by Its Toxicity. Integr J Vet Biosci Volume 5(1): 1-6. 